\title{
MOEDA, BANCOS E ATIVIDADE ECONÔMICA
}

(Material didático de uso do Grpec)

Jean Jacques Salim

MOEDA

A moeda está presente em todos os fluxos mediante os quais as atividades de produção, consumo e acumulação (ou formação de capital) se manifestam e se efetivam.

Tornando-se para exemplo uma economia moderna, não consideradas as transações externas, os principais fluxos, reais e monetários (ver figura 1) são os seguintes:

1. Os indivíduos (ou unidades familiares) fornecem recursos de produção às empresas, para o desenvolvimento das atividades de produção e distribuição de bens e serviços. Em troca, recebem pagamentos de salários, aluguéis, juros e dividendos. Com essas remunerações, adquirem bens e serviços de consumo fornecidos pelas empresas.

2. O governo recebe das empresas, dos indivíduos e dos intermediários financeiros, impostos diretos e indiretos, com os quais adquire das empresas bens e serviços de consumo e investe em formação de capital.

3. As empresas estabelecem entre si uma ampla rede de fornecimento de bens intermediários (matérias-primas) e finais (equipamentos e outros).
4. Os intermediários financeiros recebem os excedentes de renda dos indivíduos, das empresas e do governo e os repassa para financiamento do consumo dos indivíduos, do capital de giro das empresas e da formação de capital das empresas e do governo.

Figura 1- Principais fluxos reais e monetários

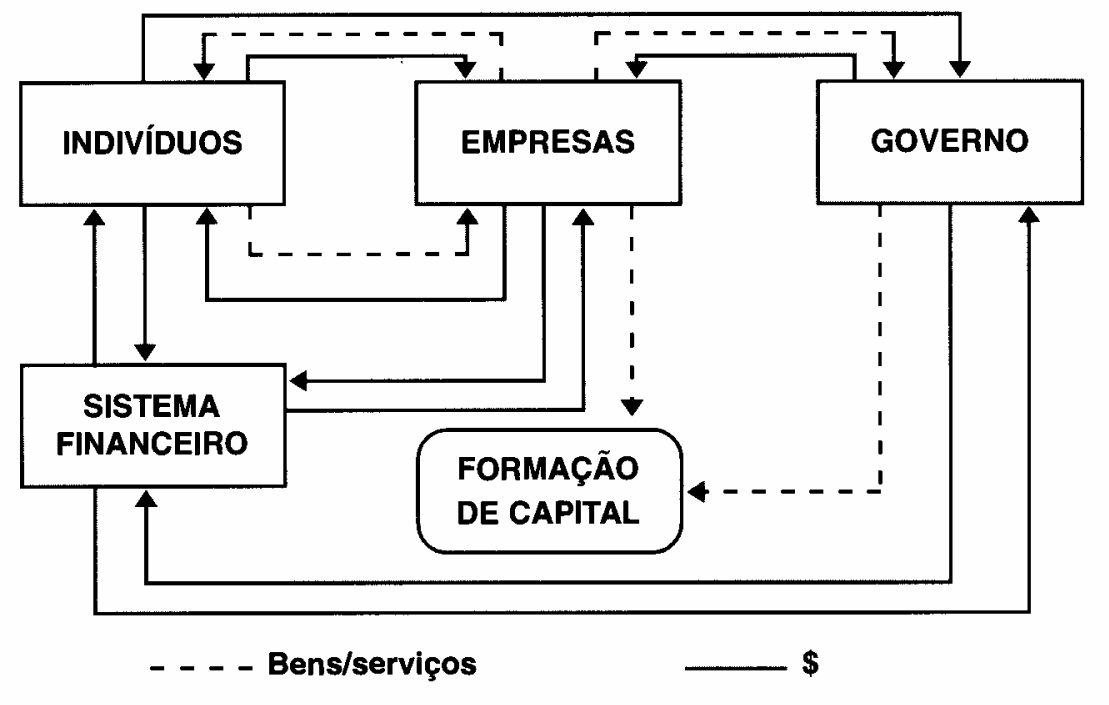




\section{BANCOS}

Para melhor entender o funcionamento do Sistema Financeiro, é conveniente dividi-lo em dois subsistemas: o subsistema monetário e o subsistema não-monetário.

O subsistema monetário, ou equivalentemente o subsistema financeiro bancário, é responsável pela geração de meios de pagamento. Os meios de pagamento existentes num sistema econômico consistem da totalidade dos haveres possuídos pelo setor nãobancário e que podem ser utilizados a qualquer momento para a quitação de dívidas. Correspondem, em suma, ao total dos ativos de liquidez imediata detido pelo setor não bancário da economia.

A definição mais usual desdobra os meios de pagamento em dois componentes:

1. O papel-moeda em poder do público (inclusive moeda metálica) - PMPP — também chamado moeda manual ou moeda corrente; e

2. Os depósitos à vista nos bancos - DV também denominados moeda bancária ou moeda escritural.

Por essa definição, é imediato que a criação de meios de pagamento só pode ser realizada:

a) pelo Banco Central, que tem o poder legal de emitir papel-moeda;

b) pelos bancos autorizados a receber depósitos à vista do público, compreendendo os bancos comerciais, os bancos múltiplos com carteira comercial e as caixas econômicas.

Depósitos à vista do público refere-se aqui aos depósitos efetuados pelos agentes econômicos não-bancários - indivíduos, empresas (inclusive as do setor de intermediação financeira não-bancária) e instituições das três esferas do governo.

A segunda porção do Sistema Financeiro, ou seja, o subsistema não-monetário, é constituída por todas as instituições de intermediação financeira não-bancária, como os bancos múltiplos sem carteira comercial; os bancos de investimento, os bancos de desenvolvimento; as sociedades de crédito, financiamento e investimento; as sociedades de crédito imobiliá- rio etc. Obviamente, tal classificação apoia-se no conceito convencional de meios de pagamento, que inclui somente a moeda corrente e a moeda escritural.

Isto posto, passa-se a examinar outros conceitos básicos para o entendimento do mecanismo de criação de moeda pelo subsistema monetário, que são os seguintes:

- Meios de pagamento, M1,conforme visto acima, são representados pelo papel-moeda em poder do público, PMPP, mais os depósitos à vista do público, DV, nos bancos autorizados:

\section{$M 1=P M P P+D V$}

- Encaixe técnico dos bancos, CX, é correspondente à parcela dos depósitós à vista guardada na caixa das instituições bancárias, como reserva de segurança.

- Reservas Bancárias, RB, são constituídas pelos depósitos compulsórios (e outros) efetuados pelos bancos junto ao Banco Central. - Base monetária, $\mathbf{B}$, é formada por três parcelas: papel moeda em poder do público, PMPP, o encaixe, CX, mantido em moeda corrente nos cofres dos bancos e as reservas bancárias, RB, depositadas no Banco Central.

$$
B=P M P P+C X+R B
$$

- Papel-moeda emitido, PME, é representativo do total da moeda legal existente, colocada em circulação pelo Banco Central, podendo encontrar-se nas mãos do público, PMPP, e/ou na caixa dos bancos, CX.

PME $=$ PMPP $+C X$

- Multiplicador, $k$, da base monetária, é o coeficiente resultante da divisão dos meios de pagamento, M1, por aquela grandeza:

$$
k=\frac{M 1}{B}
$$

O esquema apresentado na Figura 2 resume as principais relações entre essas variáveis.

Deve ser notado que a forma de distribuição dos meios de pagamento entre depósitos à vista nos bancos e papel-moeda retido em mãos 


\section{Tecnologias de Gestão}

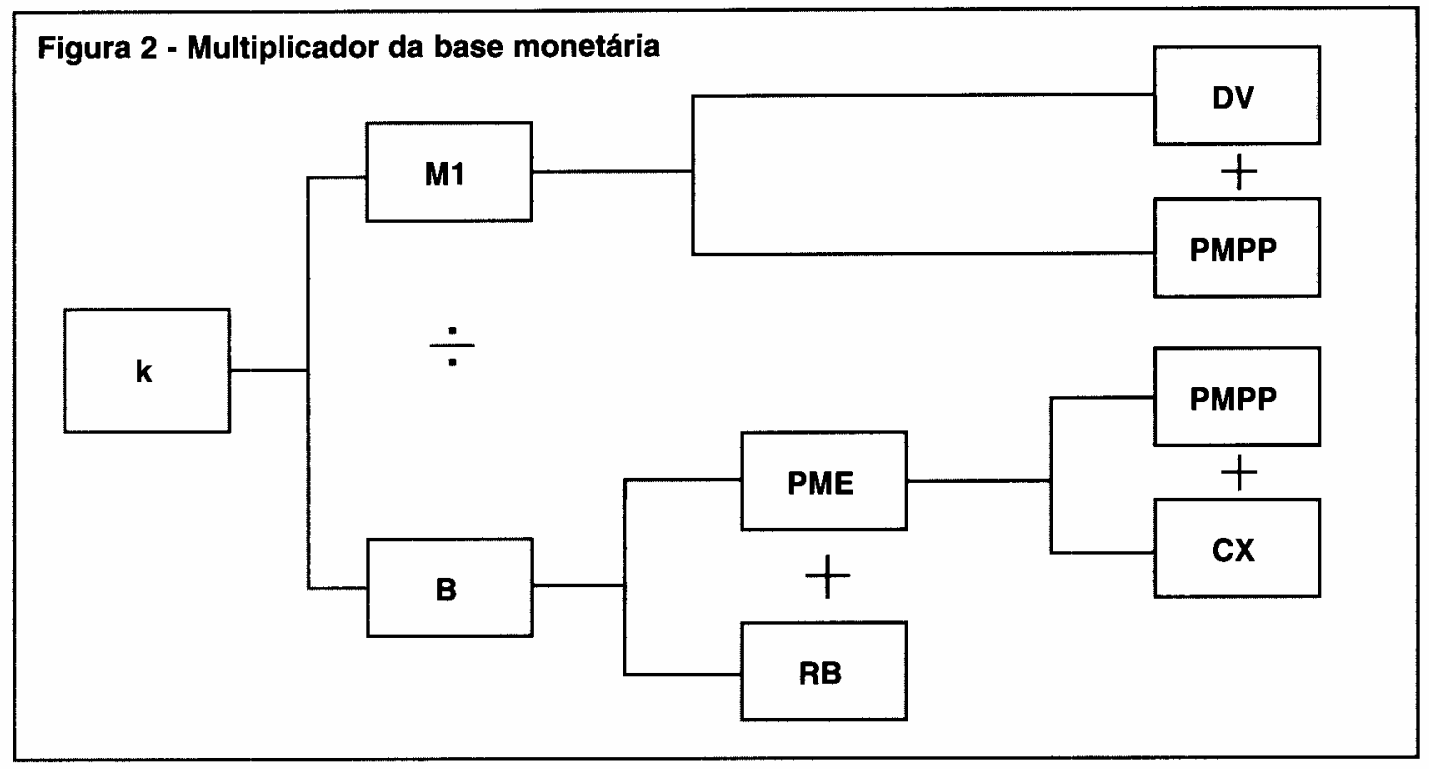

depende do comportamento do público. Da mesma forma, a destinação dada pelos bancos aos depósitos à vista, parte para encaixe, parte para atender às necessidades de reservas junto ao Banco Central e o saldo para aplicações diversas, é afetada, em grande medida, pelo comportamento dos bancos.

Com isso, se definirmos essas relações de comportamento por:

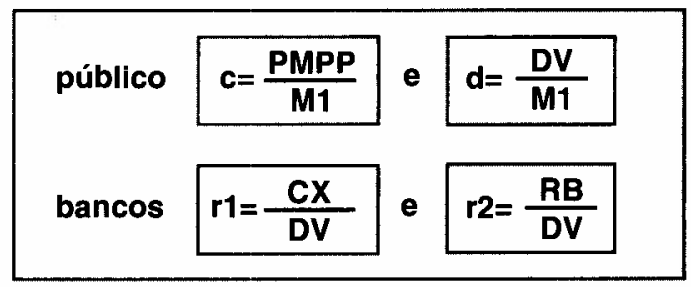

poderemos expressar a relação entre os meios de pagamento, $\mathrm{M} 1$, e a base monetária, $\mathrm{B}$, ou seja, o multiplicador $\mathrm{k}$, como sendo:

$$
\frac{M 1}{B}=k=\frac{1}{c+d(r 1+r 2)}
$$

Essa é a expressão que se encontra no Boletim do Banco Central, editado mensalmente, e que serve para o acompanhamento dos efeitos da política monetária sobre a liquidez do sistema, do ponto de vista de moeda "enquanto meio de pagamento".

Com base na publicação citada, verifica- se que os meios de pagamento, no conceito M1, totalizavam cerca de $\mathrm{R} \$ 23$ bilhões em abril de 1996, dos quais $R \$ 9,5$ bilhões encontravam-se na forma de moeda manual e $R \$ 13,5$ bilhões na forma de depósitos à vista. Na mesma data, a base monetária apresentava um saldo de $R \$ 15$ bilhões.

A alta importância da moeda escritural (depósitos à vista) na composição do $\mathrm{M} 1 \mathrm{e} o$ excedente deste sobre a base monetária são, em grande parte, explicados pelo efeito multiplicador inerente ao funcionamento de um sistema bancário calcado no regime de reservas fracionárias.

Isto porque a moeda originalmente injetada no sistema econômico por decisão do Banco Central - usualmente chamada de moeda de alto poder de expansão - tende a se transformar em depósitos bancários, enquanto uma parcela substancial de tais depósitos acabam por se transformar em empréstimos, os quais, por sua vez, tendem a retornar ao sistema bancário sob a forma de novos depósitos. Esse processo tende a se repetir indefinidamente, caracterizando a criação secundária de meios de pagamento, já que os bancos mantêm em caixa apenas uma fração (encaixe) dos depósitos captados.

Para ilustrar esse processo, imagine-se uma situação ultra simplificada, em que o Banco Central tenha decidido resgatar $\$ 200$ em títulos da dívida pública que estavam em poder de agentes não-bancários (pessoas ou empresas). Se, nesse momento, o balanço con- 
solidado das instituições bancárias, entre outras contas, mostrava $\$ 700$ de encaixe, $\$$ 3.000 de empréstimos e $\$ 3.500$ de depósitos à vista, deduz-se que a proporção desejada de encaixe é de $20 \%=\$ 700 / \$ 3.500$.

Após a injeção dos $\$ 200$ pelo Banco Central, os depósitos dos bancos se elevarão de $\$ 3.500$ para $\$ 3.700$, permitindo a essas instituições conceder novos empréstimos, uma vez que a proporção de encaixe agora é superior à desejada: $24 \%=\$ 900 / \$ 3.700=$ $24 \%$.

Admitindo-se que o mecanismo de emprestar-receber depósitos-emprestar se repita muitas vezes, ao cabo de um tempo os depósitos terão sido elevados para $\$ 4.500$ e os empréstimos para $\$ 3.800$, resultando um encaixe de equilíbrio de $20 \%=\$ 900 / 4.500$. O Quadro1 ilustra a situação antes e depois da ação do Banco Central.
De acordo com a classificação usual, os instrumentos ou meios são os seguintes:

1. Fixação da taxa de reservas dos bancos, seja a moeda mantida em caixa, $r 1=\frac{C X}{D V}$, sejam os depósitos compulsórios, $\mathrm{r} 2=\frac{\mathrm{RB}}{\mathrm{DV}}$, efetuados no Banco Central.

2. Realização de operações de mercado aberto (open market), nas quais o Banco Central compra ou vende títulos federais, injetando ou retirando do mercado moeda de alto poder de expansão. Vide exemplo anterior.

3. Realização de operações de assistência financeira de liquidez, que consistem na concessão de empréstimos aos bancos, com a finalidade de atender eventuais problemas de liquidez, de natureza circunstancial e de caráter breve.

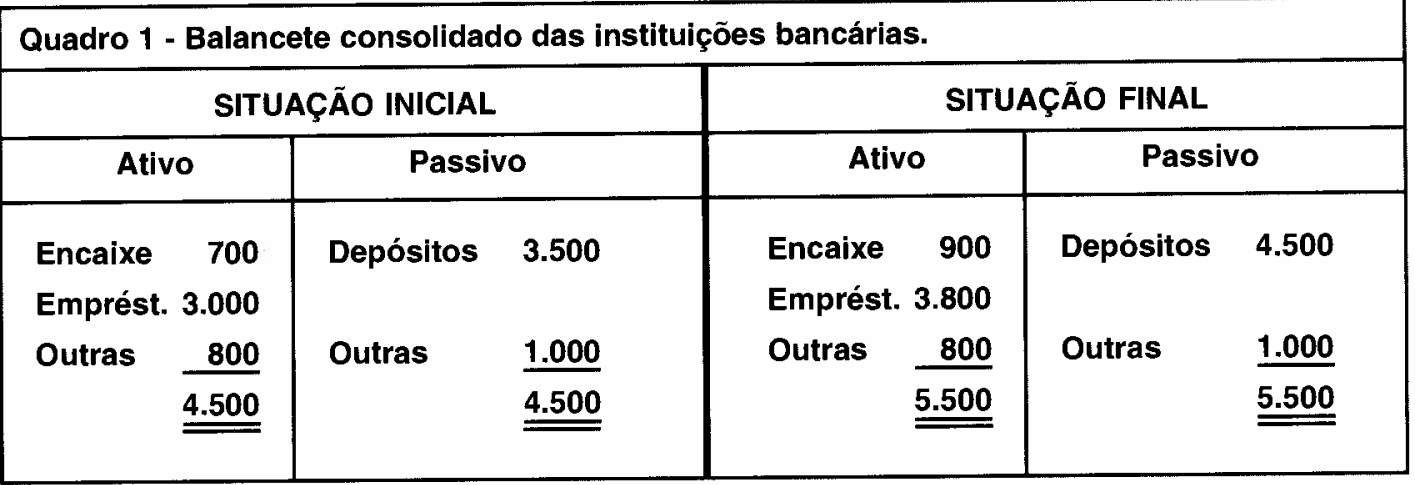

\section{Atividade Econômica}

Observa-se, através do exemplo anterior, que a oferta de moeda pode variar de um momento para o outro, por efeito de uma ação do Banco Central, como a aquisição (ou venda) de títulos governamentais junto aos agentes não bancários.

De fato, a política monetária pode ser definida como o controle da oferta de moeda (e das taxas de juros), exercido pelo Banco Central por meio de instrumentos de efeito direto ou induzido, com o objetivo de administrar a liquidez global do sistema econômico.

Pergunta-se, então:

Quais os instrumentos de que o Banco Central se vale para controlar a oferta de moeda e a taxa de juros?
4. Controle das operações de crédito, pelo qual o Banco Central introduz normas e fixa parâmetros sobre o volume e a destinação do crédito; sobre as taxas de juros; sobre os prazos, limites e condições dos empréstimos.

A figura 3 resume os efeitos dos instrumentos da política monetária sobre variáveis do mercado monetário, bem como sobre as variáveis do setor real da economia.

Para concluir esta parte, deve ficar claro que, para que determinada operação de origem a uma variação nos meios de pagamento, é preciso haver uma transação entre o subsistema bancário e o subsistema não-bancário, com troca de um haver não-monetário (HNN) por outro monetário (HN) ou viceversa. 


\section{Tecnologias de Gestão}

Figura 3 - Efeitos dos instrumentos de política monetária

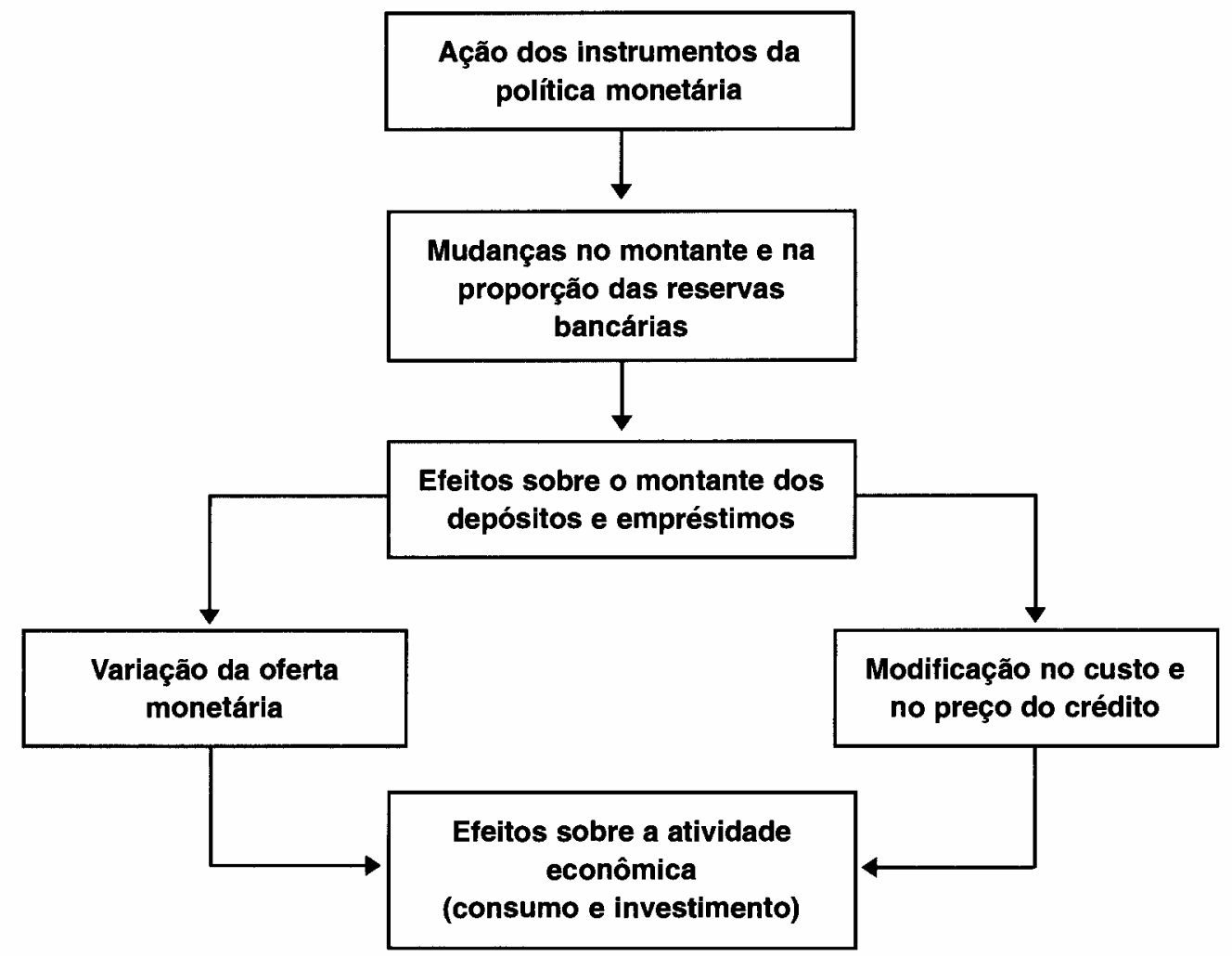

Por conseguinte, as operações interbancárias e aquelas envolvendo apenas agentes econômicos não bancários, não provocam modificações na oferta de moeda. Ressalve-se que um depósito à vista realizado por um indivíduo num banco, embora associe os dois subsistemas, não afeta os meios de pagamento, já que se trata da troca de um haver monetário (PMPP), por outro (DV), conforme figura 4.

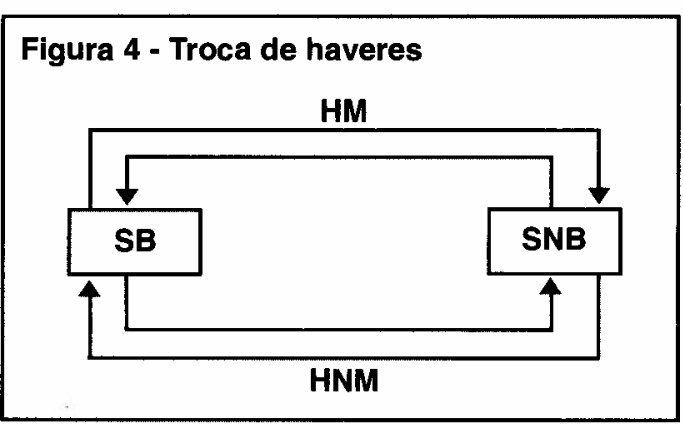

Quadro 2

M1 = Papel-moeda em poder público + depósitos à vista

+ Aplicações em cotas de fundos (FAF, FIF-CP e FRF-CP)

+ Títulos públicos (federais, estaduais e municipais) em poder do público.

= M2

+ Depósitos de poupança

$=\mathrm{M3}$

$+\quad$ Títulos privados (CDB, RDB, LC, LI)

$=$ M4 


\section{OUTRA VEZ A MOEDA}

Atenção deve ser dedicada ao fato de que o conceito estrito de moeda visto até aqui refere-se à moeda como meio de pagamento (M1 = PMPP + DV), cujas características são rendimento nulo, custo de manutenção desprezível e máxima liquidez.

Ao se acrescentar outra importante função da identificados como M2, M3, e M4. Sua composição é mostrada no quadro 2 .

Para fins de ilustração, demonstra-se nos quadros $3,4,5$ e 6 algumas estatísticas importantes acerca dos meios de pagamentos. Dados mais completos e referentes a outros períodos poderão ser consultados nos Boletins do Banco Central do Brasil.

Quadro 3 - Composição \% dos meios de pagamento (M4) em abril/96

$P M P P+D V=M 1+$ Fundos + Tít.Públ. $=$ M2 + POUP $=M 3+$ Tít.Priv. $=$ M4

$3,6 \%+5,0 \%=8,6 \%+6,2 \%+30,8 \%=45,5 \%+24,2 \%=69,7 \%+30,3 \%=100,0 \%$

Quadro 4 - Meios de pagamento em abril/96 (fim de período)

\begin{tabular}{|l|l|l|l|l|}
\hline & M1 & M2 & M3 & M4 \\
\hline R\$ bilhões & $\$ 23$ & $\$ 122$ & $\$ 187$ & $\$ 268$ \\
Composição & $8,6 \%$ & $45,5 \%$ & $69,7 \%$ & $100,0 \%$ \\
Em \% PIB & $3,4 \%$ & $17,5 \%$ & $27,1 \%$ & $39,4 \%$ \\
\hline
\end{tabular}

Quadro 5 - Composição do M1 em abril/96 (fim de período)

$\begin{array}{lllr}\text { M1 }=\$ 23,0 \text { bilhões } & \text { ou } & 100 \% \\ \text { PMPP }=\$ 9,5 \text { bilhões } & \text { ou } & 41 \% \\ \text { DV }=\$ 13,5 \text { bilhões } & \text { ou } & 59 \%\end{array}$

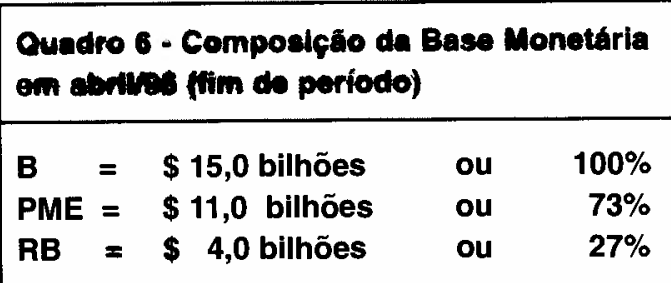

moeda, que é a reserva de valor, a definição de oferta monetária se expande para incluir uma série de outros ativos financeiros, da emissão de instituições financeiras não bancárias, títulos públicos, depósitos de poupança, depósitos a prazo, letras de câmbio etc., cujos rendimentos, custos de manutenção e liquidez são variados.

O Banco Central do Brasil, além do conceito convencional de moeda, M1, já visto, adota outros três conceitos mais abrangentes,
Referência Bibliográfica

- SIMONSEN, Mário Henrique e CYSNE, Ruben Penha. Macroeconomia. São Paulo: FGV/Atlas, 1995.

- LOPES, João do Carmo e ROSSETI, José Paschoal. Economia Monetária. São Paulo: Atlas, 1992.

- Boletim do Banco Central do Brasil

Prof. Jean Jacques Salim é Professor do Departamento de Contabilidade,

Finanças e Controle da EAESP/FGV e Coordenador do GVpec - Programa de Educação Continuada - da EAESP'FGV. 